\title{
Brian Holmes' Problem Approach: Its Highlights and Unique Features
}

\author{
Ecclesiastes Papong \\ College of Education, Zhejiang University, P.R. China
}

\begin{abstract}
This paper discusses Brian Holmes' 'Problem Approach' that is based on Karl Popper's theory of critical dualism and drawing on John Dewey's stages of reflective thinking. On top of explaining what the 'Problem Approach' is and how it works, this paper also tackles the special features of Holmes' methodology that set it apart from other methodologies. This text unveils the capabilities and features of the 'Problem Approach' that acknowledge the power of human free will with regard to its impact on the efficiency of policies. This paper also seeks to explain how the Holmesian methodology makes the testing of policy proposals possible. Keywords: Brian Holmes, Problem Approach, Comparative Education, Methodology
\end{abstract}

\section{Introduction}

Holmes reserves a "less ambitious" role to comparative education with regard to scope. ${ }^{1}$ He argues that the comparative study of education should focus on the study of a specific educational problem with the aim to analyze it in context. ${ }^{2} \mathrm{He}$ is a contemporary exponent of the 'scientific approach' to the comparative study of educational problems. He argues that the study of comparative education has to be predictive. ${ }^{3}$ He believes that the test of a good theory is its predictive usefulness. He asserts that a historical approach to comparative education cannot be used to predict what will happen in the future. History illuminates problems in the present but 'understanding' comes through the 'successful prediction rather than through the discovery of antecedent causes'. ${ }^{4}$ As how Andreas Kazamias puts it, Holmes assessed historical comparative education as being 'no substitute for scientific comparative education whose hallmark was prediction rather than explanation's. Thus, Holmes devised his 'problem approach'.

\subsection{Critical Dualism}

\section{The 'Problem Approach' And Its Highlights}

The 'problem-solving approach' enables evaluations and recommendations to be made within specified limits. The framework is based on a particular interpretation of the ideas of John Dewey (Stages of Reflective Thinking) and Karl Popper (Critical Dualism).

According to John Dewey, the function of reflective thinking is to clear up a confused situation. A number of reflective processes take place between the pre-reflective situation (confusion or perplexity) and the post-reflective situation (perplexity solved). These reflective processes reflect a hypothetico-deductive method. In this method, a solution is proposed first before gathering factors. The factors to be gathered are limited according to the context of the selected problem, to the selected time-space and to the proposed solution.

Karl Popper's 'critical dualism' asserts that in a society, two types of laws can be identified: the 'normative' and the 'sociological'. 'Normative laws' involve 'norms' which the people of a society tend to recognize and accept as holding. Although norms tend to be accepted as holding, they can still be rejected or changed by men. In principle "man is intellectually free to reject norms even if legal and other restraints are placed upon his actions'. Social norms 'do change and can be changed' and such changes are 'one source of social problems'. ${ }^{6}$

On the other hand, 'sociological laws' are unlike 'normative laws' because changes which occur in accordance with 'sociological laws' are less under man's direct control. They are 'regularities that are operating within any social environment'. If 'normative laws' involve norms, 'sociological laws' involve institutions.

'Sociological laws' make it possible to predict 'chain reactions resulting from the interaction of

\footnotetext{
${ }^{1}$ D. Mattheou, The Scientific Paradigm in Comparative Education. International Handbook of Comparative Education, 2009, p. 63.

${ }^{2}$ B. Holmes, Problems in education: a comparative approach (London: Routledge \& Kegan Paul, 1965).

${ }^{3}$ B. Holmes, Paradigm Shifts in Comparative Education, Comparative Education Review, 28(4), 1984, pp. 584-604.

${ }^{4}$ B. Holmes, Problems in education: a comparative approach (London: Routledge \& Kegan Paul, 1965), p.30.

${ }^{5}$ A. Kazamias, Forgotten Men, Forgotten Themes: The Historical-Philosophical-Cultural and Liberal Humanist Motif in Comparative Education, International Handbook of Comparative Education, 2009, p. 54.

${ }^{6}$ B. Holmes, Problems in education: a comparative approach (London: Routledge \& Kegan Paul, 1965), pp. 51-52.
} 
institutions and regularly repeated sequences of events'. ${ }^{7}$ The establishment of a pattern of 'sociological laws' provides a basis for understanding not only the operation of selected institutions but in addition, some of the processes of transformation within a society.

In addition to normative and sociological laws adopted from Popper's 'critical dualism', Holmes included 'environment' (physical factors) and 'mental state' (national character) as additions to the 'problem approach'. Physical factors such as climate and natural resources can influence educational policies so they should not be underestimated. The 'mental state' of a nation embraces the internalized value and beliefs which regulated the actions of the people and shape their world view. Knowledge of national character is significant to the researcher because it aids him to anticipate popular reactions to new policies.

\subsection{The Patterns}

Normative and institutional patterns have to be established for the 'Problem Approach'. Additional patterns - the natural environment and the nation's mental state - are not originally part of Poppers' Critical Dualism but should also be considered in Holmes' 'Problem Approach'.

The normative pattern is composed of norms and normative laws. The institutional pattern is made up of institutions and their associated sociological laws. The pattern for the environment is the information drawn from man's physical rather than social environment. The mental state of a nation represents the internalized values and beliefs that people in a group hold dearly.

\subsubsection{The construction of the normative pattern}

The empirical construct and the rational construct are the two methods used in establishing a normative pattern. Empirical construct is the collection of information by the use of questionnaires, opinion polls or other similar techniques largely developed by psychologists and sociologists. Rational construct employs philosophical techniques and sources. ${ }^{8}$ If a rational construct is well devised, it should reflect norms established by empirical techniques. The two constructs, therefore, are complementary.

After establishing the empirical or/and the rational constructs, the ideal construct and the actual construct should then be established. Given that norms do change, the features of a normative pattern are therefore bound to change over the years. Techniques of construction are needed to take account of modifications. Hence, the need to construct an ideal pattern (the basic sources) and an actual pattern (the modification of the basic sources). ${ }^{9}$

\subsubsection{The construction of the institutional pattern}

The construction of an institutional pattern has two steps. The first one is the classification of institutions (those relevant to the study) according to the major spheres such as political, economic, social and educational. Afterwards, operation of the institutions should be described. Description of their operation should be according to legal framework (the extent to which the institution is regulated by law) and statistical enquiries (e.g. per capita costs of education, pupil-teacher ratios). ${ }^{10}$

\subsubsection{The relationships within and between patterns}
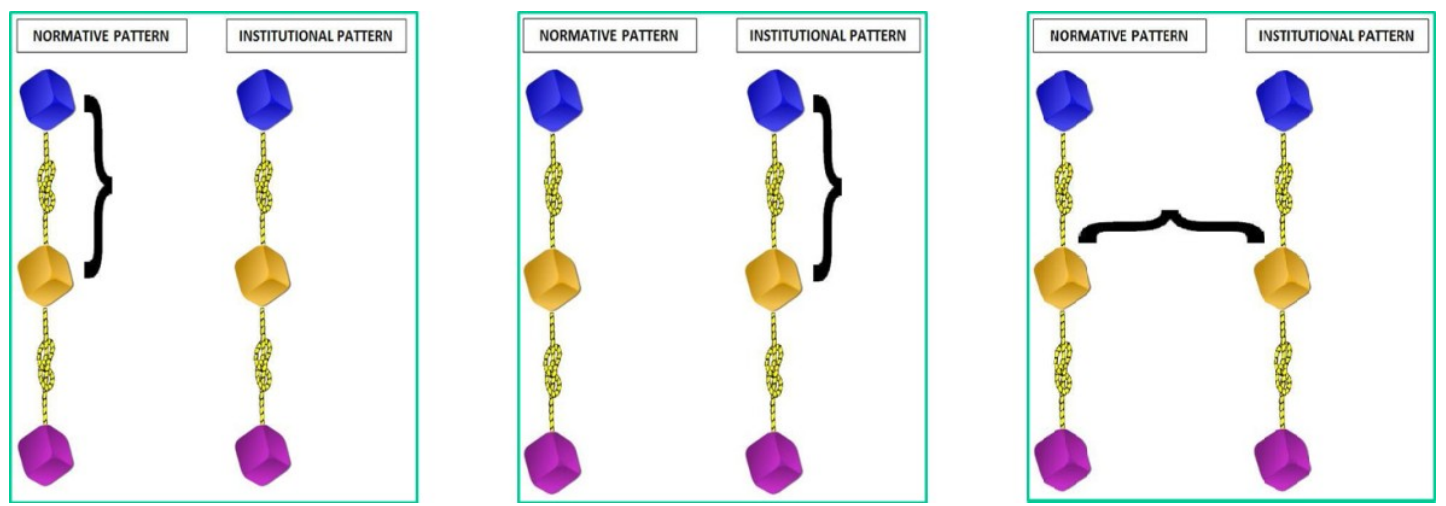

Identification and analysis of inconsistencies and social lags are made possible by the examination of relationships within and between patterns. Inconsistencies can be normative (e.g. major transformation in

\footnotetext{
${ }^{7}$ B. Holmes, Problems in education: a comparative approach (London: Routledge \& Kegan Paul, 1965), p. 52.

${ }^{8}$ B. Holmes, Problems in education: a comparative approach (London: Routledge \& Kegan Paul, 1965), pp. 54-55.

${ }^{9}$ B. Holmes, Problems in education: a comparative approach (London: Routledge \& Kegan Paul, 1965), pp. 57-61.

${ }^{10}$ B. Holmes, Problems in education: a comparative approach (London: Routledge \& Kegan Paul, 1965), pp. 62-65.
} 
philosophy combined with the retention in unmodified form of other norms), institutional (e.g. a new institution is created), or inconsistencies in theory and practice (failure to achieve in practice what is intended in theory). ${ }^{11}$

Certain features of the material/physical circumstances can also be related to aspects either of the normative or institutional patterns.

Social lag, on the other hand, is the failure of ideas, attitudes, institutions, and customs to keep pace with changes in the material culture. Lag is 'a period of time between a change's taking place in the material culture, and its adaptation in the non-material'. ${ }^{12}$

\section{The Methodology}

Holmes employs the Deweyan stages of reflective thinking. The main constituents of the 'Problem Approach' are: (1) Problem selection and analysis, (2) Formulation of policy proposals, (3) Identification of relevant factors, and (4) Anticipation and prediction of the outcome of the policy proposal.

A problem can be selected out of many classified in terms of the dominant allied discipline or under other taxonomy. With regard to the formulation of policy proposals, one task of comparative analysis is 'to make clear the range of policy choices available', and another is 'to propose more realistic solutions through refinements in the processes of analysis' ${ }^{13}$ Step 3 (identification of relevant factors within a given context), is about the patterns constructed and relationships identified through Popper's Critical Dualism. The researcher, in the end, will be able to anticipate or predict the outcomes of the policy tested.

Given that the 'Problem Approach' employs John Dewey's stages of reflective thinking, the hypothetico-deductive aspect of the methodology is therefore clearly reflected because of Deweyan pragmatism. The hypothetico-deductive method allows the researcher to gather factors according to and in the context of the hypothesis - unlike in inductionism where the hypothesis is formulated according to the factors that had been gathered beforehand. ${ }^{14}$ To cut the explanation short, the hypothetico-deductive method goes the other way around: proposed solution first before factor gathering.

\subsection{Methodology that allows testing of policy proposals}

\section{Unique Features}

'...we assume that a policy has been adopted and is to be implemented in a particular country. Our task is to predict the practical outcomes of implementing policy.' (Holmes 1965: 40)

One feature that sets the 'problem approach' a mile away from the other methodologies is that it is designed in a way that it can test existing policy proposals or researcher's self-formulated proposals. What conditions make this possible? The key is the 'patterns' that will be established based on the Popperian framework and the pragmatic feature of Holmes' methodology.

Earlier in this paper, it was mentioned that to arrive at his 'problem approach' methodology, Holmes blended the basic ideas of Deweyan pragmatism and Popperian critical dualism. Testing the formulated policy proposal is possible because a miniature 'environment' can be created in the form of patterns (normative, institutional, physical, mental state) and associated constructs (ideal and actual). The establishment of the said patterns and constructs according to the countries' context allows the researcher to create a mini 'environment' where the formulated policy can be virtually tested. Interactions and relationships in and between patterns can be unveiled, possible inconsistencies and social lags can be spotted, predicted outcomes can be made - thanks to the pragmatic feature of the methodology. It can be tested in a way as if the proposed policy would go through the 'experience' of being implemented by somehow being implemented in the 'mini-environment' that the researcher had created.

\subsection{The power of human free will is taken into account}

'Can we predict all the consequences of human action with certainty before they occur?'

Holmes responded to his own question with a no. However, he believes that 'some of the consequences of human activity can with a measure of certainty be anticipated provided the specific conditions under which the predictions are made are adequately taken into account'. ${ }^{15}$ Brian Holmes adopts the 'intermediate position

\footnotetext{
${ }^{11}$ B. Holmes, Problems in education: a comparative approach (London: Routledge \& Kegan Paul, 1965), pp. $75-83$.

${ }^{12}$ B. Holmes, Problems in education: a comparative approach (London: Routledge \& Kegan Paul, 1965), pp. 83-85.

${ }^{13}$ B. Holmes, Problems in education: a comparative approach (London: Routledge \& Kegan Paul, 1965), p. 40.

${ }^{14}$ J. Dewey, How we think (New York: Dover Publications, 1910).

${ }^{15}$ E. Epstein, The Problematic Meaning of 'Comparison' in Comparative Education, in J. Schriever \& B. Holmes (Eds), Theories and Methods in Comparative Education. (Frankfurt: Peter Lang, 1988), pp. 124-125.
} 
between pure-chance and perfect determinism'. ${ }^{16}$ As how Jason Nicholls puts it, Holmes is not only 'strongly critical of absolute determinism' but also 'critical of absolute relativism. ${ }^{17}$

Dr. Holmes mentioned that norms can be 'accepted, rejected or changed by man' ${ }^{18}$ Given the power that human decisions and thoughts have on social phenomena, Holmes took this important aspect into consideration unlike most of his peers who failed to do so. The adoption of Popper's 'critical dualism' allowed the Problem Approach to give way to the construction of the normative pattern which reflects human free will and its tendencies according to the social norm, context and interaction with institutions.

\section{Concluding Remarks}

The 'Problem Approach' highlights the problem and the proposed solution before gathering the relevant factors. While most of the other post-WWII methodologies only test hypotheses, Holmes' methodology tests proposed solutions to educational issues. His framework, composed of normative, institutional and other patterns, creates a 'mini-environment' that makes the testing of formulated solutions possible. Another aspect that distances him from his peers is that he takes account of the power of the 'free will' factor when it comes to educational phenomena. This is reflected in the ideal and actual constructs of the normative pattern. Holmes' allowed the "what people think" and the "what people want" to be part of the framework.

Brian Holmes, together with his methodology, has often been misunderstood by his peers. His attempt at using scientific terms for the comparative study of education causes confusion and so many misunderstandings. Due to his "spiky" language, academics and students alike have found him 'impossible to use'. ${ }^{19}$ I personally think that reading Holmes is not an easy task to do but once the reader gets the hang of it, he/she will be able to uncover the gems and treasures of his methodology.

\section{References}

[1] D. Mattheou, The Scientific Paradigm in Comparative Education. International Handbook of Comparative Education, 2009, pp. 5974.

[2] B. Holmes, Problems in education: a comparative approach (London: Routledge \& Kegan Paul, 1965).

[3] B. Holmes, Paradigm Shifts in Comparative Education, Comparative Education Review, 28(4), 1984, pp. $584-604$.

[4] A. Kazamias, Forgotten Men, Forgotten Themes: The Historical-Philosophical-Cultural and Liberal Humanist Motif in Comparative Education, International Handbook of Comparative Education, 2009, pp. 37-58.

[5] J. Dewey, How we think (New York: Dover Publications, 1910).

[6] E. Epstein, The Problematic Meaning of 'Comparison' in Comparative Education, in J. Schriever \& B. Holmes (Eds), Theories and Methods in Comparative Education. (Frankfurt: Peter Lang, 1988).

[7] J. Nicholls, From Antithesis to Synthesis: reinterpreting the Brian Holmes/Edmund King dialectic, Research in Comparative and International Education, 1(4), 2006, pp. 320-334. $\quad$ http://dx.doi.org/10.2304/rcie.2006.1.4.320

\footnotetext{
${ }^{16}$ E. Epstein, The Problematic Meaning of 'Comparison' in Comparative Education, in J. Schriever \& B. Holmes (Eds), Theories and Methods in Comparative Education. (Frankfurt: Peter Lang, 1988). P. 166.

${ }^{17}$ J. Nicholls, From Antithesis to Synthesis: reinterpreting the Brian Holmes/Edmund King dialectic, Research in Comparative and International Education, 1(4), 2006, pp. 320-334. http://dx.doi.org/10.2304/rcie.2006.1.4.320, p.323.

${ }_{18}^{18}$ B. Holmes, Problems in education: a comparative approach (London: Routledge \& Kegan Paul, 1965).

19 J. Nicholls, From Antithesis to Synthesis: reinterpreting the Brian Holmes/Edmund King dialectic, Research in Comparative and International Education, 1(4), 2006, pp. 320-334. http://dx.doi.org/10.2304/rcie.2006.1.4.320, p. 332.
} 